УДК 338.432+631.15.011

(C) 2013

Казарян А. Р., кандидат экономических наук

Армянский аграрный государственный университет

\title{
ПОВЫШЕНИЕ КОНКУРЕНТОСПОСОБНОСТИ КРЕСТЬЯНСКИХ ХОЗЯЙСТВ В РЕСПУБЛИКЕ АРМЕНИЯ
}

\section{Рецензент - доктор экономических наук, профессор Э. С. Казарян}

\begin{abstract}
В Армении все ещуе низок уровень конкурентоспособности крестьянских хозяйств, что обусловлено их небольиими размерами, низким уровнем государственной поддержки, развития инфраструктур, механизации и прочими факторами. По нашему мнению, повышение конкурентоспособности крестьянских хозяйств возможно благодаря оптимизации их размеров, повышению доступности кредитных ресурсов, механизации производства, внедрению эффективных систем страхования и субсидирования и т.д. В противном случае сельское хозяйство Республики Армения будет развиваться прежними медленными темпами.
\end{abstract}

Ключевые слова: крестьянские хозяйства, льготные кредиты, субсидии, страхование, кооперативы, инфраструктуры, сельское хозяйство.

Постановка проблемы. Такие особенности сельского хозяйства, как сезонный характер производства и высокая фондоемкость, иммобильность материально-технических ресурсов, используемых в аграрной сфере, высокая зависимость от природно-климатических условий, наличие постоянного риска в получении стабильных доходов, ценовая неэластичность спроса на многие продукты сельского хозяйства, большой разрыв во времени между произведенными затратами и получением продукции, существенно снижают привлекательность данной отрасли для инвесторов и потенциал ее конкурентоспособности. Необходимость обеспечения продовольственной безопасности страны, удовлетворения потребностей населения в продуктах питания и роста социально-экономической эффективности сельского хозяйства выдвигает на первый план задачу повышения конкурентоспособности отечественного агропромышленного комплекса. Без высокоэффективного и конкурентоспособного агропромышленного производства невозможно решение многих стратегических задач и формирование цивилизованного агропродовольственного рынка. На современном этапе одной из приоритетных задач развития агропромышленного комплекса является повышение его эффек- тивности и обеспечение производства конкурентоспособной продукции, которая могла бы пользоваться повышенным спросом на внутреннем и внешнем потребительском рынках. В условиях рыночной экономики выживаемость любого предприятия, его устойчивое положение на рынке товаров определяется уровнем конкурентоспособности, то есть способности производить и сбывать товары, которые по ценовым и неценовым характеристикам более привлекательны для потребителей, чем товары их конкурентов. Она характеризует возможности и динамику приспособления фирмы к условиям рыночной конкуренции. Все это не может не привлекать особого внимания к исследованию вопросов повышения конкурентоспособности сельского хозяйства в целях стабилизации конкурентных позиций армянских сельских товаропроизводителей на международном рынке, а также в виду трудностей, испытываемых отечественными производителями на внутреннем рынке в ходе конкуренции с зарубежными производителями многих видов продукции.

Конкурентоспособность сельскохозяйственной продукции во многом определяется эффективностью государственного регулирования сельского хозяйства и агропродовольственного рынка, комплексностью действия рычагов экономического механизма. При этом неэффективность одного из них может привести к низкой результативности функционирования механизма в целом. Приходится констатировать, что в постсоветский период повышение конкурентоспособности аграрной сферы за счет создания эффективно функционирующего АПК реально не стало главной задачей аграрной реформы, и уже потому данную реформу можно признать научно необоснованной, что естественно предопределило кризисное состояние агропромышленного комплекса и обусловило сокращение производства и потребления продовольствия, углубило социальную поляризацию армянского общества, усилило нарастание внешней продовольственной экспансии, снижение продовольственного потен- 
циала АПК, сокращение оперативных и стратегических продовольственных запасов.

Важный аспект конкурентоспособности - наличие конкурентных преимуществ, то есть уникальных осязаемых и неосязаемых активов, которыми владеет предприятие; они стратегически важны для бизнеса и позволяют побеждать в конкурентной борьбе. Чтобы предприятие стало лидером на рынке, ему необходимо опережать конкурентов в нововведениях в системе производства и сбыта, в установлении новых цен, снижении издержек. Поэтому конкурентоспособность не является постоянным признаком преимущество над соперником может утрачиваться со временем как за счет факторов внешней среды, так и за счет внутренних факторов. Внешними факторами конкурентоспособности являются:

- финансово-кредитная, инвестиционная и налоговая политика государства;

- степень конкурентоспособности рынка;

- величина платежеспособного спроса;

- инфраструктура рынка;

- протекционистская политика по отношению к отечественным производителям;

- стандартизация и сертификация продукции;

- уровень информированности о рыночной конъюнктуре;

- природно-климатические условия;

- внутренние факторы конкурентоспособности;

- конкурентоспособность продукции;

- финансовое состояние предприятия;

- маркетинговая деятельность;

- организация и управление производством;

- инновационная деятельность и технологии;

- размер предприятия [1].

Конкурентоспособная продукция - это продукция, обладающая более высокими свойствами, по сравнению с аналогами, и пользующаяся в результате повышенным спросом. Конкурентоспособность продукции определяется показателями ее качества, ценой, упаковкой, товарным знаком, рекламой и т.д.

Оценка конкурентоспособности сельскохозяйственной продукции на уровне государства характеризуется влиянием на ее значение макроэкономической среды, большого количества производственных, финансовых, социальных и прочих факторов, что значительно осложняет их полное отражение в количественных методиках оценки и в результате снижает их достоверность, требует дополнения качественными методами исследования.

В последние годы в Армении проблеме кон- курентоспособности отечественной продукции уделяется все больше и больше внимания. В настоящее время Республика Армения, как исторически аграрная страна, остро нуждается в стабильно развивающемся сельском хозяйстве, в том числе и в эффективно функционирующем классе фермеров-производителей. Обеспечение эффективного функционирования аграрного сектора экономики является стратегической задачей, решение которой возможно, на наш взгляд, на основе изучения опыта экономически развитых стран.

В зарубежных странах конкурентоспособность сельскохозяйственного производства обеспечивается с помощью мер государственного регулирования и государственной поддержки аграрного сектора экономики. При этом меры государственной поддержки сельского хозяйства являются приоритетными направлениями аграрной политики большинства экономически развитых стран, а система государственного регулирования сельскохозяйственного производства представляет собой один из главных рычагов повышения конкурентоспособности сельского хозяйства. Она осуществляется через меры государственной поддержки АПК, путем прямого и косвенного государственного субсидирования. Для этого используются такие типы субсидирования, как компенсационные выплаты, платежи при ущербе от стихийных бедствий, государственное регулирование цен на сельскохозяйственную продукцию, установление квот и тарифов, содействие развитию рынка и созданию фермерских объединений.

Страны ЕС расходуют значительные средства из государственного бюджета на субсидирование сельского хозяйства для обеспечения конкурентоспособности производимой продукции на международных рынках. Государство относится к фермерам как к важной части национального потенциала, ставя их на один уровень с армией и наукой. В странах ЕС к числу основных направлений поддержки сельскохозяйственных производителей относятся высокие фиксированные внутренние цены, субсидирование экспорта избыточной продукции, протекционистские меры, введение системы таможенных барьеров [9].

В Китае, например, в 2004 г. для обеспечения конкурентоспособности сельскохозяйственного производства были выделены финансовые ассигнования в размере 150 млрд юаней, что составляло 18,1 млрд долларов США. Дополнительные финансовые средства были выделены на поддержку реформы сельских налогов и сборов; 
на экологическое строительство в лесном и водном хозяйстве; на развитие социальной защиты на селе, включая образование сельской молодежи и здравоохранение; на сельское инфраструктурное строительство и социально-экономическое развитие [5].

В экономически развитых странах размеры государственной поддержки сельского хозяйства остаются достаточно высокими на протяжении многих лет. К примеру, в США они находятся в пределах 27-40 \%, в Канаде - на уровне 35 \%, в Швеции - $47 \%$, в Финляндии и Японии - $70 \%$, в Швейцарии - 76 \%, в Норвегии - $95 \%$ от стоимости продукции. Это вызвано рядом обстоятельств и, прежде всего, стремлением государства поддерживать цены на продовольственные товары на общественно приемлемом уровне, что делает их доступными для большей части населения [1].

Кроме того, существуют различные способы предоставления налоговых льгот по земельному налогу. В странах ЕС для предприятий сельского хозяйства применяются льготы при выплате налога на добавленную стоимость.

Разнообразие применяемых налогов позволяет регулировать разные стороны аграрного производства, его развитие и повышение конкурентоспособности.

Не менее важным рычагом государственного регулирования экономики в экономически развитых странах выступает сельскохозяйственный кредит. Сезонность сельскохозяйственного производства обуславливает всевозрастающую потребность в ссудном капитале.

В США наибольшие льготы в размере $1 \%$ сроком на 35-50 лет предоставляются малоимущим фермерам и сельским жителям в рамках программы по улучшению жилищных условий. Фермеры, пострадавшие от стихийных бедствий, могут получить кредит на покупку техники и оборудования, пополнение стада, кормов, семян и удобрения, на погашение долгов по движимому имуществу по льготной процентной ставке (4-4,5 \%). В Великобритании для финансирования сельскохозяйственного производства в основном выдается кредит со ставкой в $12 \%$; в Нидерландах - в 5,7 \%; в Германии - в 6-8,5 \%. Во Франции процентные ставки зависят от срока действия ссуды, ее категории и устанавливаются в пределах 8-10\% [6].

Особого внимания заслуживает опыт США по субсидированию сельского хозяйства. Бюджетные расходы США на сельское хозяйство зависят от экономической ситуации - в кризисные годы их значение резко возрастает, в более стабильные периоды уровень государственного субсидирования заметно снижается. Так, в связи с кризисом 1980-1985 годов бюджетные расходы на сельское хозяйство в 1986 году составили 58,7 млрд дол., или 5,9 \% от всего федерального бюджета. Конец 80-х годов был благоприятным для сельского хозяйства, и уровень государственного субсидирования заметно снизился, составив в 1989 году 52 млрд дол., или 4,6 \% федерального бюджета. Бюджетные средства выделяются на финансирование следующих программ:

- сельскохозяйственные исследования;

- организация маркетинга и информация о рынках и ценах;

- кредитование;

- консервация и изъятие земель;

- поддержка цен, закупка, компенсационные платежи;

- поддержка фермерских снабженческих и сбытовых кооперативов;

- рыночные заказы;

- субсидирование продовольствия;

- экспортные субсидии;

- международная продовольственная помощь.

В структуре расходов федерального бюджета на сельское хозяйство главными являются два направления:

1) программы стабилизации доходов (на них приходится около $60 \%$ бюджетных расходов по статье «Сельское хозяйство»);

2) программы сельскохозяйственных исследований и обслуживания науки.

Необходимо отметить, что наибольшую долю помощи (около 70 \% бюджетных средств) получают относительно крупные хозяйства, обеспечивающие высокую эффективность ведения производства, а фактически бюджетным финансированием охвачена одна треть американских ферм [6].

В процессе оказания сельскохозяйственным товаропроизводителям государственной помощи и поддержки наряду с кредитованием производителей немаловажное значение приобретает развитие системы страхования.

Как известно, при стихийных бедствиях и неблагоприятных погодных условиях сельское хозяйство несет колоссальные убытки, что затрагивает интересы как сельскохозяйственных производителей, так и государства в целом. Поэтому государственное страхование предусматривает комплексное решение целого ряда задач, в частности: компенсирование материальных затрат, 
покрытие убытков, оказание эффективной финансовой помощи в восстановлении нормальной производственной деятельности. В наибольшей степени страховые услуги развиты в Америке, доля рынка которых достигает почти половины от общемирового объема услуг. За ней следуют Япония $(11,25 \%)$, Германия $(11,19 \%)$ и Великобритания $(5,93 \%)$ [6].

В США государство оплачивает четверть административных расходов, связанных с выдачей страховой премии фермерам. Бюджетные средства на уплату доли государства в страховом взносе перечисляются непосредственно в страховые компании. Общие рамки тарифов по страхованию определяются Законом «О защите от сельскохозяйственных рисков» [9].

В Испании при министерстве сельского хозяйства создано государственное учреждение сельскохозяйственного страхования. Министерства сельского хозяйства и финансов определяют порядок возмещения сельскохозяйственным товаропроизводителям части страховых взносов, процент налога и общую сумму помощи. Во Франции Национальный гарантированный фонд возмещает потери тем сельскохозяйственным товаропроизводителям, у которых они превышают $27 \%$ по отдельным культурам и $14 \%$ - по всей продукции. Половина средств этого фонда формируется за счет страховых взносов товаропроизводителей. При страховании урожая $50 \%$ взносов вносит товаропроизводитель, $25 \%$ провинциальное правительство и $25 \%$ - государственный бюджет [1].

Сельское хозяйство Республики Армения рассматривалось как наиболее важная отрасль хозяйства, и именно с нее в 1991 г. начались экономические преобразования. В процессе реформ предполагалось сделать ее структурой с оптимальным сочетанием различных форм собственности и регулируемой рыночными отношениями эффективной и стабильной отраслью.

Принятые в 1990 г. Закон РА «О собственности» и в 1991 г. «О крестьянских и коллективных крестьянских хозяйствах» и ряд других законов стали правовой основой аграрных преобразований. В результате применения этих законов были ликвидированы более 860 колхозов и совхозов, приватизированы принадлежащие им земля и другие средства производства. В результате были созданы крестьянские и коллективные крестьянские хозяйства, основанные на частной собственности на землю и иные средства производства. Аграрная реформа в Армении преследовала следующие принципиальные цели:
- ликвидацию государственной монополии на землю и другие средства производства и создание на селе конкурентной системы различных форм собственности с преобладанием частной;

- ликвидацию государственных сельскохозяйственных организаций и создание самоуправляемых, самофинансируемых структур с новыми, наиболее эффективными и гибкими формами хозяйствования;

- формирование в аграрной отрасли рыночных, свободных экономических отношений.

В конечном счете, реализация указанных принципов была направлена на повышение заинтересованности и ответственности крестьянина, активизацию его творческих инициатив.

Однако процесс реформирования сельского хозяйства был сложным и противоречивым.

Реформа 1991 г. сделала первые практические шаги в формировании укладов аграрной экономики. В результате образовались новые формы хозяйствования - крестьянские (фермерские) хозяйства.

Крестьянские хозяйства, в отличие от фермерских, носят потребительский характер, обладают иным мотивационным механизмом.

Во-первых, крестьянское хозяйство основывается на индивидуальной или мелкогрупповой, премущественно семейной форме организации труда. Такого рода деятельность по производству сельскохозяйственной продукции ориентирована прежде всего на потребление продукции внутри самого хозяйства и не требует юридического оформления хозяйственной деятельности и ведения официальной отчетности [2].

Перерастание такого рода хозяйств в фермерские связано с развитием новых технологий, повышением уровня механизации, общей и профессиональной культуры крестьян.

Предполагалось, что в последующие годы должна была быть обеспечена непрерывность реформ и проводиться активная политика по совершенствованию форм хозяйствования, оптимизации размеров хозяйств посредством действенного рынка земли и создания кооперативов, совершенствованию правового поля для развития производственной инфраструктуры и разработки основополагающих принципов государственного содействия.

Однако, по существу аграрные реформы в Армении ограничились лишь приватизацией. В итоге по прошествии двадцати лет по объему валового сельскохозяйственного продукта и ряду других показателей аграрная отрасль Армении уступает дореформенному уровню. Из года 


\section{EKOHOMIKA}

в год повышаются цены на сельскохозяйственную продукцию. Около 160 тысяч гектаров пахотных земель выпали из активного оборота и используются в качестве сенокосов и пастбищ.

Обзор литературных источников по данной проблеме. Теоретические и методологические основы конкуренции и конкурентоспособности раскрыты в работах представителей различных экономических школ, среди которых следует выделить А. Смита, Д. Рикардо, А. Маршала, Д. Ж. Кейнса, И. Макконела, П. Самуельсона, Ф. Хаека, Й. Шумпетера, Г. Азоева, Р. Фатхутдинова и др.

Применительно к аграрной сфере экономики эти вопросы рассматрываются в работах А. Алтухова, И. Буровскина, В. Гончарева, В. Милоседева, Л. Оверчук, А. Попцова, А. Ткача, И. Ушакова и др. [9].

Цель исследования: выявить уровень развития, особенности и конкурентоспособность сельскохозяйственных организаций в аграрной сфере Республики Армения; выработать концептуальные и методические подходы к обоснованию условий повышения конкурентоспособноси сельскохозяйственного производства.

Результаты исследования. В настоящее время эффективной деятельности крестьянских хозяйств препятствуют:

- недостаточное государственное содействие крестьянским хозяйствам;

- высокая ставка по кредитам;

- высокие налоги;

- низкий уровень механизации;

- недостаточная обеспеченность материальнотехническими средствами;

- крайне мелкие размеры крестьянских хозяйств;

- раздробленность земельных наделов;

- низкий уровень развития инфраструктуры;

- несовершенство правовой и страховой систем, трудности с реализацией готовой продукции;

- высокий уровень рисков;

- несовершенство рынка земли и т. д.

Проблемы повышения конкурентоспособности отечественной продукции являются одними из наиболее сложных и актуальних. По нашему мнению, повышение конкурентоспособности крестьянских хозяйств и вообще хозяйствующих субъектов в аграрной отрасли возможно лишь в результате разработки и реализации комплекса правовых, организационно-хозяйственных и социальных мероприятий. Основным механизмом обеспечения продовольственной безопасности на устойчивой основе является производство конкурентоспособной национальной сельскохозяйственной продукции. В свою очередь, конкурентоспособность отечественной продукции может быть достигнута только путем осуществления целенаправленной государственной политики. Развитие аграрного предпринимательства в стране может кардинально измениться лишь при разумном государственном регулировании сельского хозяйства с обязательным соблюдением интересов сельскохозяйственных товаропроизводителей. Специфика функционирования агропромышленного комплекса, обеспечение продовольственной безопасности требуют проведения такой агропродовольственной политики, в которой государственное регулирование и государственная поддержка должны играть большую роль, чем в других отраслях экономики.

В первую очередь, необходимо усовершенствовать правовое поле, регулирующее аграрную отрасль, и принять ряд законов, регламентирующих правовые отношения в аграрной отрасли. Считаем целесообразным принятие следующих законов Республики Армения:

- «О государственном регулировании аграрной отрасли». Принятием этого зкона будут регламентированы принципы и приоритеты государственного содействия, целевые объекты выделения бюджетных средств, принципы предоставления привилегий и т. д.;

- «О кооперативах». Этот закон поможет созданию новых эффективных методов хозяйствования, формированию кооперативов и укрупнению размеров хозяйств.

В СНГ и ряде других стран уже принят закон «О крестьянских (фермерских) хозяйствах». Между тем в Армении ни один закон не регулирует деятельность крестьянских хозяйств, а Гражданский кодекс не регламентирует статус крестьянских хозяйств [4].

С этой точки зрения считаем целесообразным принятие Закона РА «О крестьянских (фермерских) хозяйствах», в котором будет установлен статус крестьянских хозяйств и будет регламентирован процесс их создания и функционирования.

В Республике Армения крестьянские хозяйства отличаются своими размерами: на долю одного хозяйства в среднем приходится 1,37 га земли. Этот показатель по республике колеблется в пределах 0,6-3,0 га, а сами земельные угодья, в свою очередь, разбиты на 4-6 участков. В подобных условиях не может быть и речи об эффективности капитальных вложений, совершенствовании производства и организации труда, т.е. о повы- 
шении конкурентоспособности.

Между тем, как показывает международный опыт, крупные хозяйства имеют ряд преимуществ перед мелкими, и в развитых странах намечается тенденция к укрупнению размеров крестьянских хозяйств. К примеру, в США средний размер земельных угодий фермеров достигает 200 га; конкурентоспособными считаются 600 га, а перспективными являются фермеры, владеющие 1500 га земли. В Великобритании эти показатели, соответственно, равны 55, 80 и 200 га, во Франции, Дании и Швеции - 25, 50 и 100 гектаров [8].

Хозяйства относительно больших размеров более конкурентоспособны и всегда выделялись высокой товарностью, высоким уровнем производительности труда и отдачи капитальных вложений, большими возможностями для решения социальных проблем и т. д.

Для повышения эффективности функционирования сельскохозяйственных кооперативов необходимо формирование хозяйств оптимального размера и оптимизации размеров земельных угодий реформируемых предприятий.

В мировой практике существует два способа укрупнения производства:

- увеличение размеров фермерских хозяйств путем купли и продажи земли, т. е. создания рынка земли;

- создание кооперативов.

Создание кооперативов позволит решить целый ряд проблем продовольственной безопасности страны, обеспечит занятость сельского населения, смягчит социальную напряженность и, самое главное, обеспечит демографический рост (особенно в приграничных районах) и укрепит обороноспособность страны. Для Армении создание кооперативов имеет исключительно важное значение из-за мелкоконтурности крестьянских хозяйств. В отдельных сельскохозяйственных зонах (Арарат, Армавир) их площадь составляет 0,6-0,7 га. Исследования показали, что на таких площадях крайне низки уровень механизации работ и эффективность производства, проблематично использование высокопроизводительной техники и внедрение передовых технологий и т. д.

Создание прочной законодательной базы, по нашему мнению, не может быть достаточным условием для организации кооперативов. Наряду с этим необходимо проводить серьезную организационно-методическую и разъяснительную работу среди сельского населения.

В целях стимулирования создания кооперати- вов как эффективной формы хозяйствования целесообразно проводить следующие мероприятия:

- возместить из бюджета часть расходов, связанных с их созданием;

- субсидировать из бюджета часть процентных ставок на предоставляемые кооперативам кредиты со стороны коммерческих банков;

- на ближайшие несколько лет установить для кооперативов низкую арендную плату за использование государственных резервных пахотных земель и пастбищ;

- создать кооперативам льготные условия для использования местного сырья и ресурсов;

- в ближайшие несколько лет субсидировать из государственного бюджета часть страховых выплат кооперативов;

- на государственном уровне предоставить бесплатную информацию о ситуации на внешнем и внутреннем рынках, оказать консультационную помощь по самым разнообразным проблемам (правовые, экономические и прочие вопросы);

- для кооперативов, осуществляющих инвестиционную деятельность, установить низкие или нулевые таможенные тарифы на ввоз техники и внедрение технологий;

- создать страховые и лизинговые компании с долевым участием государства;

- предоставить субсидии из государственного бюджета не в расчете на обрабатываемые сельскохозяйственные угодья, а на производимую сельхозпродукцию;

- освободить от земельного налога те крестьянские хозяйства, которые в данном году увеличивают уставной капитал по меньшей мере на 50 \% собственных активов;

- освободить от налога на прибыль те банки, которые больше половины своих активов направляют на кредитование приоритетных, с точки зрения государства, сельскохозяйственных отраслей или эффективных форм хозяйствования (фермерские хозяйства и кооперативы);

- в первоочередном порядке заключать договоры о госзакупках с кооперативами и крупными фермерскими хозяйствами для поощрения прогрессивных методов хозяйствования и с целью укрупнения производства;

- в течение ближайших трех-пяти лет для лизинговых и страховых компаний установить налог с прибыли ниже 50 \% или вообще освободить их от уплаты налога;

- с целью формирования института финансирования аграрной сферы и предоставления сель- 
скохозяйственным предприятиям долгосрочных и по низким процентным ставкам или беспроцентных кредитов в Республике Армения, создать государственный фонд. Источниками финансирования последнего могут служить средства, образованные от приватизации, ассигнования из государственного бюджета, льготные кредитные ресурсы, поступающие из международных финансовых организаций и т. д.

Во многих странах мира арендные отношения являются одной из самых эффективных форм использования земли. При этом в отсутствие развитого земельного рынка арендные отношения становятся главным инструментом перераспределения земли между эффективно хозяйствующими товаропроизводителями и бережного и рационального ее использования. В Республике Армения арендные отношения регулируются Гражданским кодексом, который, однако, подробным образом не регламентирует механизмы арендования земли. В нем не установлены мининимальный и максимальный размеры арендования, предъявляемые арендатору требования, которые позволят произвести объективный отбор и предоставить землю предприимчивым хозяйственникам. Одновременно в законе не оговариваются форма проведения конкурса и критерии, согласно которым будет определен победитель [4]. Из-за несовершенства законодательства Республики Армения очень часто землей распоряжаются недостаточно предприимчивые хозяйственники, не ведется достоверный учет земель государственного резервного фонда, органы местного самоуправления допускают злоупотребления и т.д. Одним из приоритетных направлений земельно-экономической политики является регулирование арендных отношений, направленное на повышение эффективности управления и распоряжения землями, находящимися в государственной и муниципальной собственности.

Для эффективного использования в Армении сельскохозяйственных угодий и, в первую очередь, земель резервного фонда предлагаем: принять Закон РА «Об арендовании» или внести изменения в Гражданский кодекс. Подробное регламентирование арендных отношений позволит предприимчивым хозяйственникам арендовать землю и повысить уровень эффективности производства.

Условием формирования конкуренции в АПК является также развитие инфраструктуры - производственной, социальной и рыночной. Производственная инфраструктура должна обеспечить сохранность и наращивание производства сельхозпродукции. Для этого требуется улучшить обеспеченность предприятий и фермерских хозяйств техникой, производственными помещениями, энергетическими мощностями, газом, дорогами. Развитие аграрного предпринимательства, в том числе и фермерского сектора, невозможно без формирования развитой социальной инфраструктуры села, выражающейся через строительство жилья, школ, дошкольных учреждений, объектов культуры и здравоохранения, торговли и бытового обслуживания, автомобильных дорог, электрификацию, газификацию, телефонизацию, водоснабжение, теплоснабжение и т. д. Развитие социальной инфраструктуры позволит: повысить материальное благополучие сеьского населения; улучшить состояние здоровья жителей села; повысить образовательный уровень населения; повысить стабильность института семьи; снизить степень развития процессов деградации населения; повысить уровень социальной безопасности жизни в сельской местности. Развитый рынок предусматривает развитую систему информационного обеспечения товаропроизводителей. Недооценка этого компонента приводит к резкому снижению конкурентных способностей агропромышленных предприятий.

Выводы. Повышение конкурентоспособности крестьянских хозяйств - это, в первую очередь, понимание нужд потребительского рынка и перспектив его развития; знание возможностей конкурентов, анализ тенденций развития окружающей среды; способность создать товар с такими качествами, чтобы потребитель предпочел его, а не товар конкурента. Это и повышение качества продукции, которое является главным показателем деятельности любого производства. В широком понимании качеством продукции называется совокупность свойств товара или услуги удовлетворять потребности, соответствующие ее назначению. При этом повышение уровня качества продукции диктует повышение спроса на нее и увеличение суммы прибыли не только за счет объема продаж, но также за счет повышения цены на товар более высокого качества. Экономические преобразования требует перехода на новое качество роста в аграрной сфере, связанное с формированием рациональной структуры агробизнеса, повышением уровня агротехнологий, переходом к маркетинговой стратегии сельскохозяйственного производства, импортозамещению на внутреннем рынке, активизации экспорта в страны ближнего и дальнего зарубежья. 


\section{БИБЛИОГРАФИЯ}

1. Аймен А. T. Зарубежный опыт обеспечения конкурентоспособнности крестьянских хозяйств. www.rusnauka.com./7nmw.../

2. Бирюков B. Реструктуризация в сельском хозяйстве и эффективность различных форм собственности / Международный сельскохозяйственный журнал. -2000 . - № 5. - С. 55-59.

3. Буянов А. Зарубежный опыт организации арендных отношений / Международный сельскохозяйственный журнал. - 2001. - № 3. - С. 33-37.

4. Гражданский кодекс Республики Армения // Официальный бюллетень РА 17 (50). - Ереван, 1998.
5. Экономическая история мира / Под редакцией М. В. Конотопова. - T. IV. - М. : Кнорус, 2008. C. 148,178 .

6. Конкурентоспособность США. Обзор. - М. : Экономика, 1988. - С. 37.

7. Мадиев Г. Методологические основы формирования и функционирования конкурентоспособных сельхозформирований / Проблемы агрорынка. - 2002, январь -март. - С. 41-42.

8. Серова Е. В. Аграрная экономика. - М. : Тандем, 1999. - С. 54.

9. Юданов А. Конкуренция: теория и практика. М. : Тандем, 1996. - С. 272. 